\title{
O Bacilo Imortal
}

\section{Resenha de O fascismo eterno, de Umberto Eco}

Sergio Schargel

Resenha recebida em 22/08/2020 e aprovada em 13/11/2020.

O fascismo é eterno. Enquanto existir sociedade de massas, seu bacilo estará sempre presente. Pode estar adormecido, entorpecido, mas espera apenas uma oportunidade conveniente para retornar. Nesses retornos, manifesta características distintas, dissimuladas, escondidas, mas mantém alguns dos velhos hábitos que o permitem ainda ser identificado. Essa é a tese principal de Umberto Eco em O fascismo eterno, reciclada posteriormente por outros autores como Jason Stanley e Rob Riemen, principalmente após o início da onda marrom de recessão democrática global na metade da década passada.

Um ponto interessante do ensaio é a alternância entre relatos pessoais e tópicos teóricos, sobrepondo um ao outro. Eco começa sua obra falando um pouco de sua infância na Itália, durante o fascismo "original", contando um pouco de suas próprias experiências com o regime, como, por exemplo, um de seus primeiros prêmios literários conquistados, com a redação Devemos morrer pela glória de Mussolini e pelo destino da Itália?. De forma irônica, afirma que era um garoto esperto. Um estilo irônico que, aliás, é marca sua não apenas neste ensaio, mas em sua obra em geral.

A pequena anedota no início do livro serve para ilustrar como o fascismo absorve, através de promessas e ideias de heroísmo grandioso, cidadãos comuns. Prossegue o autor afirmando que foi só depois da morte de Mussolini, que tinha sido reconduzido ao governo italiano como fantoche após a invasão alemã, que tomou consciência do que era o fascismo. Só depois de libertado, Eco conhece a libertação. Mas por que as pessoas, na ascensão do fascismo, tanto desejam a sua prisão retórica, mesmo cientes da armadilha que ele oferece? Essa é a principal questão que o livro do semiólogo italiano busca responder.

Para começar, entendendo que o fascismo não é um movimento hermético limitado à Itália da década de 20 a 40, Eco ${ }^{\text {II }}$ afirma que o fenômeno dificilmente se repetiria da mesma forma atualmente. Isso não significa, porém, que ele esteja morto. Um movimento tão poderoso não simplesmente desaparece com o dia, seria ingênuo acreditar na sua morte em 45. Regimes morrem, mas suas heranças permanecem, mesmo que enrustidas. No caso particular da Itália, o fascismo nunca sequer chegou a adormecer de fato, basta recordar que, embora fragilizado, o MSI, partido herdeiro do fascismo, permaneceu na cena italiana e cresceu em força após a disseminação de movimentos neofascistas na década de 70, inspirando inclusive o já clássico ensaio de Pasolini sobre os vaga-lumes da resistência antifascista. Mais ainda, após um racha o MSI se tornou Allianza Nacionale e acabou sendo, no início da década de 2000, absorvido para um governo de coalização na Itália, se tornando o primeiro partido abertamente fascista a retornar ao poder após $45^{\mathrm{III}}$.

A maior força da obra está em sua recusa de limitar o fascismo à experiência italiana, mesmo sem, simultaneamente, elasticizar de forma excessiva o conceito, 


\section{O BACILO IMORTAL}

\section{RESENHA DE O FASCISMO ETERNO, DE UMBERTO ECO}

\section{SERGIO SCHARGEL}

evitando o erro de deturpá-lo. Eco ${ }^{\mathrm{IV}}$ é enfático ao apontar que cada fascismo é idiossincrático da nação e época em que surge, ao passo em que mantém alguns pontos interseccionais entre todas as suas manifestações. Admitir isso, segundo o autor, é o primeiro passo para poder combatê-lo; evitando justamente o erro comum de acreditar que, pelas diferenças no contexto geopolítico contemporâneo e pela suposta solidez democrática, o fascismo não pode reaparecer.

É importante também notar que, além de não incorrer na falácia de apontar o fascismo como limitado a um espaço-tempo específico, Eco também contorna outros erros comuns em obras sobre movimentos anti-democráticos: o de insistir que esses movimentos tomam o poder sempre através de um golpe de Estado, violento e sangrento. Steven Levitsky e Daniel Ziblatt ${ }^{\mathrm{V}}$, por exemplo, em Como as democracias morrem, assim como David Runciman ${ }^{\mathrm{VI}}$ em Como a democracia chega ao fim, apesar de se referirem a personagens como Mussolini e Hitler, tratam o processo de fragilização democrática gradual, ao invés do tradicional golpe rápido, como se fosse um processo inédito. Ignorando, porém, que tanto Mussolini quanto Hitler ascenderam politicamente através de mecanismos legais ${ }^{\mathrm{VII}}$. Hoje como antigamente, grande parte dos fascistas chegam ao poder sem efetivamente infringir constituições.

E não somente no método empregado para corroer a democracia se repete $a d$ eternum: a reação do establishment e da esquerda também ${ }^{\mathrm{VIII}}$. Assim como na ascensão de Mussolini e Hitler, o establishment, no tangente à ascensão de políticos evidentemente anti-democráticos contemporâneos como Trump ou Bolsonaro, os tratou como um problema menor, que ocasionalmente acabaria sendo controlado e absorvido pelas estruturas e instituições. O repetido jargão "o contexto geopolítico contemporâneo é muito complexo para que se aconteça a mesma coisa", é um fiel retrato de como a apatia fermentou no crescimento dos fascismos contemporâneos.

Embora rapidamente, Eco debate ainda a relação do fascismo com o totalitarismo. Embora ambos sejam comumente confundidos como a mesma coisa, são consideravelmente distintos entre si. Nem todo fascismo é totalitário, assim como nem todo totalitarismo é fascismo. O nazismo, por exemplo, foi um fascismo totalitário; ao passo que o fascismo italiano não ${ }^{\mathrm{XIX}}$. Em parte, isso se deve graças à própria debilidade do fascismo italiano, contraditório em si próprio, um ponto que é reforçado, além de Eco, por outros pensadores como Robert Paxton ${ }^{\mathrm{X}}$ em Anatomia do fascismo. Esse aspecto, inclusive, seria posteriormente retomado por outros autores que se dedicaram ao estudo do fascismo, como Madeleine Albright ${ }^{\mathrm{XI}}$ e Jason Stanley ${ }^{\mathrm{XII}}$, que buscam compreendê-lo menos como um sistema político e mais como uma metodologia de poder. Isto é, em parte devido a fragilidade de sua ideologia - o poder veio primeiro, a ideologia depois -, torna-se difícil entender o fascismo como um sistema comparado ao liberalismo, socialismo ou conservadorismo, por exemplo, com ideologias claras e definidas, valores universais localizados, cada qual com seu respectivo arquiteto intelectual. Mesmo o nazismo, por si próprio uma ramificação do fascismo, possuía o Mein kampf como manifesto de uma doutrina que antecede uma movimentação política de fato, ao menos se for ignorado o desorganizado putsch da cervejaria de Hitler. $\mathrm{O}$ fascismo, ao contrário, surge primeiro para ser pensado depois ${ }^{\text {XIII }}$. Ele é a resposta de um tempo, o lado sombrio da democracia de massas, uma virtualidade possível em 


\section{O BACILO IMORTAL}

\section{RESENHA DE O FASCISMO ETERNO, DE UMBERTO ECO \\ SERGIO SCHARGEL}

qualquer lugar e época após 1920 , como se viria a descobrir ${ }^{\mathrm{XIV}}$. Mussolini apenas nomeou uma metodologia de poder e um movimento que já existia. $\mathrm{O}$ fascismo rotulou um movimento internacional inevitável que existiria com qualquer nome que o fosse dado. Como Eco diz: "O fascismo não era uma ideologia monolítica, mas antes uma colagem de diversas ideias políticas e filosóficas, um alveário de contradições."XV

Eco $^{\mathrm{XVI}}$ lista 14 possíveis características do fascismo, algumas certamente inerentes, como o ultraconservadorismo, outras menos e passíveis de questionamento, como o léxico pobre. Outrossim, deixa claro que elas não são necessariamente obrigatórias de todas as manifestações. Grande parte são, inclusive, contraditórias, além de pertencerem a outras formas de autoritarismo. Outras são reconhecíveis em qualquer proposta de "fascismo mínimo". Essas características elásticas explicam em parte porque o fascismo se tornou, para muitos, sinônimo de autoritarismo, embora sejam conceitos absolutamente distintos.

O encerramento do ensaio é premonitório, dado que foi escrito antes do início da recessão democrática global $^{\mathrm{XVII}}$ : aponta as novas faces de um fascismo em geral dissimulado, enrustido, escondido. Um fascismo que tem vergonha de se assumir como tal, embora compartilhe de muitas das características destacadas pelo autor. Um fascismo que parafraseia Mussolini ${ }^{\text {XVIII }}$ e Goebbels ${ }^{\mathrm{XIX}}$, como no caso brasileiro, mas, através de manobras retóricas e falsas citações, procura relacionar o próprio movimento antifascista ao fascismo ${ }^{\mathrm{XX}}$. Fascismos com caras de fascismo, jeito de fascismo, ideologia de fascismo, retórica de fascismo, mas que se nega fascista. Um fascismo que, mesmo se refundasse o Partido Nacional-Socialista, ainda rejeitaria o rótulo de fascista ou nazista, preferindo apenas ser chamado de populista de extrema-direita ultraconservador e ultranacionalista. Ignorando que, em interseção de todos os pontos levantados por Umberto Eco, o fascismo é justamente um populismo ultraconservador e ultranacionalista.

\section{Notas}

\footnotetext{
${ }^{\text {I }}$ Mestrando em Literatura pela PUC-Rio, mestrando em Ciência Política pela UNIRIO. Bolsista CNPq. Bacharel em Comunicação Social, Jornalismo e Comunicação Social, Publicidade e Propaganda, ambas pela PUC-Rio. Sua pesquisa e produção artística são focadas na relação entre literatura e política.

${ }^{\mathrm{II}}$ ECO, Umberto. O fascismo eterno. Rio de Janeiro: Record, 2018, p. 23, 60-61.

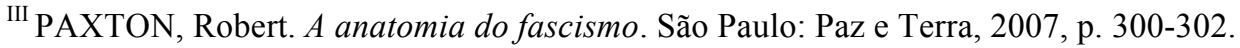

IV ECO, Umberto. O fascismo eterno. Rio de Janeiro: Record, p. 43.

${ }^{\mathrm{V}}$ ECO, Umberto. O fascismo eterno. Rio de Janeiro: Record, p. 15.

${ }^{\mathrm{VI}}$ ECO, Umberto. O fascismo eterno. Rio de Janeiro: Record, p. 11.

${ }^{V I I}$ PAXTON, Robert. A anatomia do fascismo. São Paulo: Paz e Terra, 2007, p. 250.

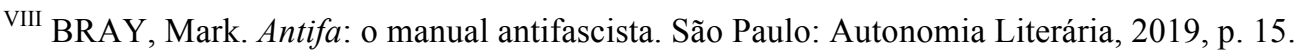




\section{O BACILO IMORTAL}

\section{RESENHA DE O FASCISMO ETERNO, DE UMBERTO ECO \\ SERGIO SCHARGEL}

${ }^{\mathrm{IX}}$ ECO, Umberto. O fascismo eterno. Rio de Janeiro: Record, p. 26-27.

X PAXTON, Robert. A anatomia do fascismo. São Paulo: Paz e Terra, 2007, p. 36.

XI ALBRIGHT, Madeleine. Fascismo: um alerta. São Paulo: Planeta, 2018, p. 28.

XII STANLEY, Jason. Como funciona o fascismo: a política do "nós" e "eles". Porto Alegre: L\&PM, 2018, p. 14.

XIII SCHARGEL, Sergio. "Fascism is once more at our doors, and we still refuse to see and treat it by its name": an interview with Cultural Philosopher Rob Riemen. Revista Cantareira, n. 33, 2020. Disponível em: https://periodicos.uff.br/cantareira/article/view/40711.

XIV SCHARGEL, Sergio. "Fascism is once more at our doors, and we still refuse to see and treat it by its name": an interview with Cultural Philosopher Rob Riemen. Revista Cantareira, n. 33, 2020. Disponível em: https://periodicos.uff.br/cantareira/article/view/40711.

${ }^{\mathrm{XV}}$ ECO, Umberto. O fascismo eterno. Rio de Janeiro: Record, p. 32.

${ }^{\mathrm{XVI}}$ ECO, Umberto. O fascismo eterno. Rio de Janeiro: Record, p. 44-58.

${ }^{X V I I}$ FREEDOM HOUSE. New report: Freedom in the world 2020 finds established democracies are in decline. Freedom House. Disponível em: https://freedomhouse.org/article/new-report-freedom-world2020-finds-established-democracies-are-decline. Acesso em 06 jul. 2020.

XVIII UOL. Bolsonaro compartilha vídeo com famosa frase atribuída a Mussolini. UOL. Disponível em: https://noticias.uol.com.br/politica/ultimas-noticias/2020/06/01/bolsonaro-posta-video-facebook.htm.

Acesso em 22 jul. 2020.

XIX GÓES, Bruno; ARAGÃO, Helena; SOARES; Jussara. Roberto Alvim copia discurso do nazista Joseph Goebbels e causa onda de indignação. $O$ Globo. Disponível em: https://oglobo.globo.com/cultura/roberto-alvim-copia-discurso-do-nazista-joseph-goebbels-causa-ondade-indignacao-24195523. Acesso em 24 jul. 2020.

XX TRIGUEIRO, Gabriel. Eduardo Bolsonaro, pare de citar Churchill errado. Revista Época. Disponível em: https://epoca.globo.com/coluna-eduardo-bolsonaro-pare-de-citar-churchill-errado-23948620. Acesso em 27 jul. 2020.

\section{Referências}

ALBRIGHT, Madeleine. Fascismo: um alerta. São Paulo: Planeta, 2018.

BRAY, Mark. Antifa: o manual antifascista. São Paulo: Autonomia Literária, 2019.

ECO, Umberto. O fascismo eterno. Rio de Janeiro: Record, 2018.

FREEDOM HOUSE. New report: Freedom in the world 2020 finds established democracies are in decline. Freedom House. Disponível em: https://freedomhouse.org/article/new-report-freedom-world-2020-finds-establisheddemocracies-are-decline. Acesso em 06 jul. 2020. 
O BACILO IMORTAL

RESENHA DE O FASCISMO ETERNO, DE UMBERTO ECO

SERGIO SCHARGEL

GÓES, Bruno; ARAGÃO, Helena; SOARES; Jussara. Roberto Alvim copia discurso do nazista Joseph Goebbels e causa onda de indignação. $O$ Globo. Disponível em: https://oglobo.globo.com/cultura/roberto-alvim-copia-discurso-do-nazista-josephgoebbels-causa-onda-de-indignacao-24195523. Acesso em 24 jul. 2020.

LEVITSKY, Steve; ZIBLATT, Daniel. Como as democracias morrem. Rio de Janeiro: Zahar, 2018.

PAXTON, Robert. A anatomia do fascismo. São Paulo: Paz e Terra, 2007.

SCHARGEL, Sergio. "Fascism is once more at our doors, and we still refuse to see and treat it by its name": an interview with Cultural Philosopher Rob Riemen. Revista Cantareira, n. 33, 2020. Disponível em: https://periodicos.uff.br/cantareira/article/view/40711.

RIEMEN, Rob. O eterno retorno do fascismo. Lisboa: Editorial Bizâncio, 2012.

RUNCIMAN, David. Como a democracia chega ao fim. São Paulo: Todavia, 2018.

STANLEY, Jason. Como funciona o fascismo: a política do "nós" e "eles". Porto Alegre: L\&PM, 2018.

TRIGUEIRO, Gabriel. Eduardo Bolsonaro, pare de citar Churchill errado. Revista Época. Disponível em: https://epoca.globo.com/coluna-eduardo-bolsonaro-pare-decitar-churchill-errado-23948620. Acesso em 27 jul. 2020.

UOL. Bolsonaro compartilha vídeo com famosa frase atribuída a Mussolini. UOL. Disponível em: https://noticias.uol.com.br/politica/ultimasnoticias/2020/06/01/bolsonaro-posta-video-facebook.htm. Acesso em 22 jul. 2020. 